\title{
- A Glimpse of COVID-19 Situation in Thailand
}

\section{Pongsak Rattanachaikunsopon*, Parichat Phumkhachorn}

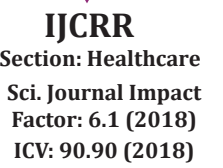

Department of Biological Science, Faculty of Science, Ubon Ratchathani University, Thailand 34190

Email: rattanchaikunsopon@yahoo.com

There are seven strains of coronaviruses known to cause diseases in human. Four of them, HKU1, NL63, 229E and OC43, are causative agents of common cold with mild symptoms that can be controlled by supportive care. The other three strains, SARS-CoV, MERS-CoV andSARS-CoV-2, are believed to be mutated strains derived from animal coronaviruses. They cause serious diseases in human that kill many lives and result in enormous damage in global economy. ${ }^{1,2}$

At present, coronavirus SARS-CoV-2, the causative agent of the disease named corona virus disease 2019 (COVID-19), affects about 218 countries and territories around the world, causing more than one million of deaths. This disease was first found in Wuhan city, China and reported to the WHO (World Health Organization) by the end of 2019. Several cases of pneumonia with unfamiliar etiology were sent to local hospitals. All of them had record of visiting Hunan seafood market where many live animals such as bats, snakes and rabbits were sold. In January 2020, the National Health Commission of China announced that the pneumonia was caused by a novel coronavirus. It was named by the place of outbreak as Wuhan corona virus. The source of this novel coronavirus is inconclusive because its genetic sequence was found to be closely related to genetic sequences of coronaviruses found in bat, snake and pangolin. In February 2020, the International Committee on Taxonomy of Viruses (ICTV) named the virus as SARS-CoV-2 and the disease as COVID-19. Further investigation revealed that SARSCoV-2 could transmit from person to person due to close contact with infected persons especially aerosols derived from coughing, sneezing and exhaling. The pandemic of the disease occurred due to the lack of awareness of its highly infectious capability. Travelers were allowed to go in and out of the countries with infected persons, causing the spreading of the disease worldwide. The pandemic of COVID-19 was announced by WHO in March 20202.,3,5

Situation of COVID-19 in Thailand began on 12 January 2020 when the Health Ministry of Thailand reported the first COVID-19 case found in Thailand. She travelled from Wuhan to Suvarnabhumi International Airport, Thailand with high temperature. Real time reverse transcription PCR confirmed that she had SAR-CoV2. Since then, no pragmatic plan or regulation was assigned to cope the disease. Luckily, no significant increase in number of COVID-19 cases was observed. Up until the beginning of March 2020, a super spreader incident was reported. The site of the incident was the Lumpini boxing stadium, one of the largest boxing stadium in Thailand. A SAR-CoV-2 infected boxing fan accidentally appeared in the stadium packed with people watching the 6th March boxing championship matches. From this incident, more than 50 people, including boxing officials and fans and those closely associated with them have been confirmed to have COVID-19. During March and April 2020, the number of COVID-19 cases in Thailand exponentially increased urging Thai government to set up the Center for COVID-19 Situation Administration (CCSA) and announce the state of emergency to keep controlling the spread of COVID-19 in Thailand. The restrictions mentioned in the announcement include a continuation of the nationwide curfew from $22.00 \mathrm{pm}$ to $04.00 \mathrm{am}$, and the ban on gatherings and group activities. Furthermore, wearing masks and social distancing have been strictly practiced in Thailand. After these actions, COVID-19 cases in Thailand have increased but at a very low rate, an average less than 10 cases per days, from May until November 2020. Almost all of the cases were people coming from outside of Thailand. Transmission among people residing Thailand was rarely found. This suggests that COVID-19 control strategies in Thailand are effective. From the emergence of the first COVID-19 case in Thailand in January 2020 until the end of November 2020, Thailand has less than 70 death cases out of the 5,000 accumulated COVID-19 cases.

For the COVID-19 vaccines development situation in Thailand, twenty prototype vaccines have so far developed. Six of them have already been tested on primates. However, the progress is far behind the COVID-19 vaccines development in Europe, USA and China. Therefore, Thailand's National Vaccine Committee has set aside about three billion baht to be able to purchase adequate supplies of the vaccines from overseas. 
Thailand is currently in the right track of controlling COVID-19 within the country. It is due to the Government's strategies and collaboration of people. The only thing needed to be concerned is how to prevent COVID-19 infections illegally coming into Thailand from nearby countries where COVID-19 situations are still questionable. If all endogenous and exogenous factors are well managed, it is believed that COVID-19 situation in Thailand will be in control until the availability of COVID-19 vaccines. After the emergence of the vaccines, it is interesting to see how much impact the vaccines really have on COVID-19 situation in Thailand.

Key Words: COVID-19, SAR-CoV-2, Thailand, WHO

\section{REFERENCES}

1. Singhal T. A review of coronavirus disease-2019 (COVID-19). Indian J Pediatr 2020; 87: 281-286.

2. Cui J, Li F, Shi Z. Origin and evolution of pathogenic coronaviruses. Nat Rev Microbiol 2019;17(3):181-192.

3. Yi Y, Lagniton PNP, Ye S, Li E, Xu RH. COVID-19: What has been learned and to be learned about the novel coronavirus disease. Int J BiolSci 2020; 16(10):1753-1766.

4. Shereen A, Khan S, Kazmi A, Bashir N, Siddique R. COVID-19 infection: Origin, transmission, and characterization. J Adv Res 2020;24:91-98.

5. Yuen KS, Ye ZW, Fung SY, Chan CP, Jin DY. SARS-CoV-2 and COVID-19: The most important research questions. Cell Biosci 2020;10:40. 